\title{
Tackling a Tough Question: Who is the Emerging Psychopath?
}

\section{Jamie L Flexon*}

\author{
Department of Criminology and Criminal Justice, Green School of International and Public Affairs, Florida
}

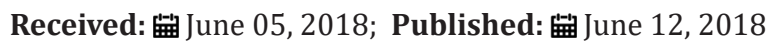

*Corresponding author: Jamie L Flexon, Department of Criminology and Criminal Justice, Green School of International and Public Affairs, Florida International University, Florida 33199, USA

\section{Opinion}

Defining who the nascent or emerging psychopath is tied to an unfortunate reality. There is no uniformly accepted definition of the concept, which is tied to debate in the literature. As some have argued, and rightfully so, the most common measures for psychopathy are operating in a theoretical vacuum and the measures have been confused with the construct [1,2]. This is the opposite of how this should work, as the construct should inform the measure. Little ground in conceptually defining psychopathy will be made as long as clinicians and researchers continue to move forward as though this issue has been resolved. Since some claim to use the work of Hervey Cleckley [3] to inform their work and measures of psychopathy, it seems prudent to go to the source when discerning the features of psychopathy. Through several editions of Cleckley's seminal work, The Mask of Sanity, the concept of psychopathy was refined. In his fifth edition, Cleckley [3] offers the following:

Before going on to the perhaps still unanswerable questions of why the psychopath behaves as he does or of how he comes to follow such a life scheme, let us, as was just suggested, attempt to say what the psychopath is in terms of his actions and his apparent intentions, so that we may recognize him readily and distinguish him from others.

We shall list the characteristic points that have emerged and then discuss them in order (p. 338-339):
a. Superficial charm and good "intelligence"
b. $\quad$ Absence of delusions and other signs of irrational thinking
c. Absence of "nervousness" or psychoneurotic manifestations
d. Unreliability
e. Untruthfulness and insincerity
f. Lack of remorse or shame
g. Inadequately motivated antisocial behavior
h. Poor judgment and failure to learn by experience
i. Pathologic egocentricity and incapacity for love

j. General poverty in major affective reactions

k. Specific loss of insight

l. Unresponsiveness in general interpersonal relations

m. Fantastic and uninviting behavior with drink and sometimes without

n. Suicide rarely carried out

o. Sex life impersonal, trivial, and poorly integrated

p. Failure to follow any life plan

Cleckley's work references youth repeatedly when presenting case studies for illustrative purposes. This makes obvious sense as he regards psychopathy as a personality disorder that necessarily manifests from an early age, and he ties these case studies back to the characteristic list. As noted, since the final iterations of Cleckley's book, a number of scholars have turned to his conceptual formulation of psychopathy. However, there is clear departure over time. This can be traced to difficulties in conceptually defining some of the characteristics he proposed and a reliance on behavioral indicators for anti-social personality disorder (ASPD) used in the DSM developed by the American Psychiatric Association. It is important to note, without getting too far off track that psychopathy and ASPD were treated as one in the same in the DSM, and Cleckley treated them as synonymous. He specifically refers to the changing nomenclature of the American Psychiatric Association from the first edition of his book to the fifth edition in noting, "The classification of psychopathic personality was changed to that of sociopathic personality in 1958. In 1968 it was changed again to antisocial personality. Like most psychiatrists I continue to think of the people who are the subject of this book as psychopaths and will most often refer to them by this familiar term. Sociopath or antisocial personality will sometimes appear, used as a synonym to designate patients with this specific pattern of disorder" [3].

Under current criteria, a youth may not be diagnosed with psychopathy-and or ASPD as the individual must be aged 18 to 
formally receive the official diagnosis. This does not mean that it isn't happening - though reserving such a designation should be avoided. Acquiring the psychopath label, even informally and especially among youth, can have catastrophic ramifications and delay the implementation of strategies aimed at ameliorating any associated problems that may or may not belong to being a psychopath. Further, and related to the above, failing to accurately identify the psychopathic individual creates a situation whereas clear, well-defined characteristics are not appreciated, and more and more individuals are added to the ranks of those that can be included as being psychopathic because of the varied criteria. This makes it very difficult to isolate treatment protocols.

Fundamentally, the question becomes whether you are treating a psychopathic individual or someone that resembles a psychopathic individual. Some may believe that this is not an issue if the end result looks the same. However, looks can be deceiving. Here, a youth may be dissociating from early trauma and or having behavioral problems and overtly look like a psychopath. Is this youth a psychopath? Is there a differential feature? This potential for confounding is important to recognize. In essence, are you really addressing intrinsic shallow affect and lack of empathy or are you addressing more externalizing behaviors, such as juvenile delinquency?-both features are indicators of psychopathy in the most common measurement tool, and as noted above, there is real concern that we are conflating the definition of the concept with the measurement $[1,2]$.

\section{Is Criminal Behavior a Discerning Feature of Psychopathy?}

A common inclination is to use behavioral measures, in part, to define psychopathy along with the affective dimensions, such as Callous Unemotional (CU) traits. This often appears as an artifact of measurement schemes and is the most recognized in the literature and in practice. It has been argued, however, that it results in capturing an all too inclusive group of people that may be subjected to the label. Very simply, doing certain behaviors, particularly anti-social and criminal ones, may not be a sensitive enough indicator for psychopathy. This is important and there are real world consequences. The label of psychopathy carries with it very negative overtones along with a belief that it is resistant to treatment. In The Mask of Sanity, Cleckley differentiates the psychopath from the typical criminal [3] and from other character and behavior disorders, including delinquency [3 (p 262-263)].

Many people, perhaps most, who commit violent and serious crimes fail to show the chief characteristics which so consistently appear in the cases we have considered. Many, in fact, show features that make it very difficult to identify them with this group. The term psychopath (or antisocial personality) as it is applied by various psychiatrists and hospital staffs sometimes becomes so broad that it might be applied to almost any criminal. I (comment omitted) maintain that the large group of maladjusted personalities whom I have personally studied and to whom this diagnosis has been consistently applied differs distinctly from a group of ordinary criminals. The essential reactive pattern appears to be in many important respects unlike the ordinary criminal's simpler and better organized revolt against society and to be something far more subtly pathologic. It is my opinion that when the typical psychopath, in the sense with which this term is here used, occasionally commits a major deed of violence, it is usually a casual act done not from tremendous passion or as a result of plans persistently followed with earnest compelling fervor. There is less to indicate excessively violent rage than a relatively weak emotion breaking through even weaker restraints. The psychopath is not volcanically explosive, at the mercy of irresistible drives and overwhelming rages of temper. Often he seems scarcely wholehearted, even in wrath or wickedness [3].

The first point that Cleckley makes here is an important one. Concerning behavior, juvenile delinquency or anti-sociality may manifest in many conditions and situations without the individual having to be a psychopath. The behavior and other manifestations would be, essentially, secondary to some primary condition or circumstance. For example, a youth dissociating as a consequence of abuse may also engage in anti-social behaviors and bear essential resemblance to the psychopath, such as having impulsivity problems or other maladaptive coping mechanisms because of turbulent rearing. This individual may be responsive to tailored treatments because they possess the capacity to change. Whether an actual psychopath has the ability to respond to treatment is still in question. Failing to deal with this issue of definition and the resulting over inclusion will ultimately harm the ability to develop and evaluate treatment protocols.

The next point is equally important. The behavior is a manifestation of the personality, whereas there is a weak impulse met with weaker constraints over behavior. This lack of selfcontrol does not necessarily translate into criminal behavior, but may certainly underlie anti-social behavior. Given this, disagreement exists among scholars about whether or not deviant and or criminal behavior should be included as an indicator or dimension of psychopathy $[1,2,4]$. As noted, one side of the debate considers criminal and problem behavior central to the construct [5], while others contend that deviant and "criminal behavior is an epiphenomenon that is neither diagnostic of psychopathy nor specific to personality deviation"-rather, criminal and violent behavior, in particular, is viewed as a later, downstream correlate of psychopathy [1 (p. 433)]. As discussed, this later position strongly echoes early theorizing about the character of psychopathy.

Cleckley's [3] conception of successful and unsuccessful psychopaths over 70 years ago was largely informed by examining non institutionalized subjects, whereas those meeting the criteria of being egocentric, irresponsible, and using superficial charm were not necessarily criminal or institutionalized and were considered high functioning [6]. He also recognized the tension that presented with using juvenile delinquency and criminality in youth for diagnostic purposes. Cleckley noted [3 (p.270)]: Confused manifestations of revolt or self-expression are, as everyone knows, 
more likely to produce unacceptable behavior during childhood and adolescence than in adult life. Sometimes persistent traits and tendencies of this sort and inadequate emotional responses indicate the picture of the psychopath early in his career. Sometimes, however, the child or the adolescent will for a while behave in a way that would seem scarcely possible to anyone but the true psychopath and later change, becoming a normal and useful member of society. Such cases put a serious responsibility on the psychiatrist.

At the same time, Karpman [7] argued that many being labeled with psychopathy were being ascribed so inappropriately. Karpman [7] very sharply criticized this tendency to label those exhibiting anti-social behavior as a part of the diagnostic criteria for psychopathy because similar behavior can be tied to a plethora of disorders including bipolar disorder, schizoid disorders, metabolic disturbances, to name a very few. In essence, by including deviant/ criminal behavior within the construct (as well as a number of other traits he dismisses), the label of psychopathy was being inappropriately applied since any number of psychic and medical disturbances could manifest with problem, abhorrent behavior. Thus, virtually any condition that co-manifested with aggression, violence or behavioral outbursts could result in misapplying psychopathy, leading to a great amount of over inclusion. Hence, it was through such a lens that Karpman (1948) further clarified his discussion of heterogeneity in psychopathy. The point is that not all individuals with psychopathic personality features are violent, aggressive, or engage in criminal behavior, [3,8]. This issue is augmented when considering youth for whom anti-social behavior and or delinquent acts become, to some extent, more normative through adolescence (e.g., age-crime curve).

What is juvenile psychopathy, then? It depends on who you ask. It would seem prudent, since we are talking about the manifestation of a personality disorder, to restrict the definition to characteristics that are consistent with the level of core, individual personality features that are essential to the disorder. According to some scholars and in deference to theorists, such features would include traits of emotional detachment, such as callousness, shallow affect, remorselessness, lack of empathy, egocentricity, and low trait anxiety (for discussion see [1]. A differential feature may be the presence or absence of anxiety. While some use this presence of anxiety to differentiate between primary or secondary psychopathy, it may be that this feature can alert us to whether we are dealing with a psychopathic individual or one better included under the criteria for some other co morbid condition.

So, the definition of psychopathy remains elusive as it is entangled in scholarly camps-which are even more complicated when it is extended to youth. For clinical purposes, and irrespective of whether the diagnosis can be made to anyone under 18-yearsold, there is obvious deference to the DSM, and many accept the status quo to further clinical and research objectives. Others remain committed to sorting through this fundamental obstacle of definition. Ironically, taking stock of the literature results in more questions concerning which findings are accurate, artifacts of measurement, relevant, and or comparable. Since youth are the concern here, it is worth emphasizing (again) that it is quite normative for juveniles to engage in anti-social behaviors (i.e., agecrime curve) and environmental exposures can shape the form of that behavior. Since a number of youth who score as psychopathic on current, common measures also seem to age-out of their psychopathy, then more attention clearly needs to be paid to how we are measuring psychopathy, particularly in youth.

\section{How Many Psychopathic Youth are there?}

Discerning how many psychopathic-like youth there are is difficult owning to differences in the measures used to capture psychopathy and the varying populations (community, institutional) examined. For studies using behavioral items in measures used to identify psychopathy, it makes sense to use institutionalized samples as a means to capture a large population of psychopaths for research purposes. However, not everyone agrees with these measures and looking solely at institutionalized youth may miss those psychopathic-like youth that either avoid detection of their criminality or don't engage in it. As such, some studies examining psychopathic-like youth have specifically sought to look at the general population instead of institutionalized samples in efforts to identify and study any unknown or underappreciated populations associated with psychopathy.

For illustration, (Figure 1) provides estimates from a community sample. The data are culled from the National Institute of Child Health and Human Development (NICHD)'s Study of Early Child Care and Youth Development (SECCYD). Note, the organization is not associated with this writing or any reported findings. The measures for the psychopathic-like youth (primary-like and secondary-like) are constructed from the Youth Psychopathic Traits Inventory's (YPTI) subscales of remorselessness, un emotionality, and callousness (CU Traits) developed by Andershed, Kerr, Stattin and Levander [9] in concert with an anxiety scale to isolate those resembling the primary and secondary variants of psychopathy in the population of youth at large. Note, anxiety is often used to identify and differentiate variants of psychopaths.

The figure represents 3 categories: non-psychopathic youth, and primary and secondary variations of the disorder (variants). initially the primary type may be considered as (arguably) innately psychopathic, while there are more questions surrounding the etiology of the secondary type youth. According to this sample of youth taken from the general population, 20\% would fall into the psychopathic-like category when using callousness and unemotional features of psychopathy and the presence or absence of anxiety for variant identification. This is a significant number, would counter the idea that psychopathy is rare, and reflects the difficulty of capturing the personality disorder in youth. If anxiety is excluded as a defining feature of psychopathy (primary youth), which aligns more with adult conceptions of the disorder, then the estimate of psychopathic youth is $4.8 \%$. 


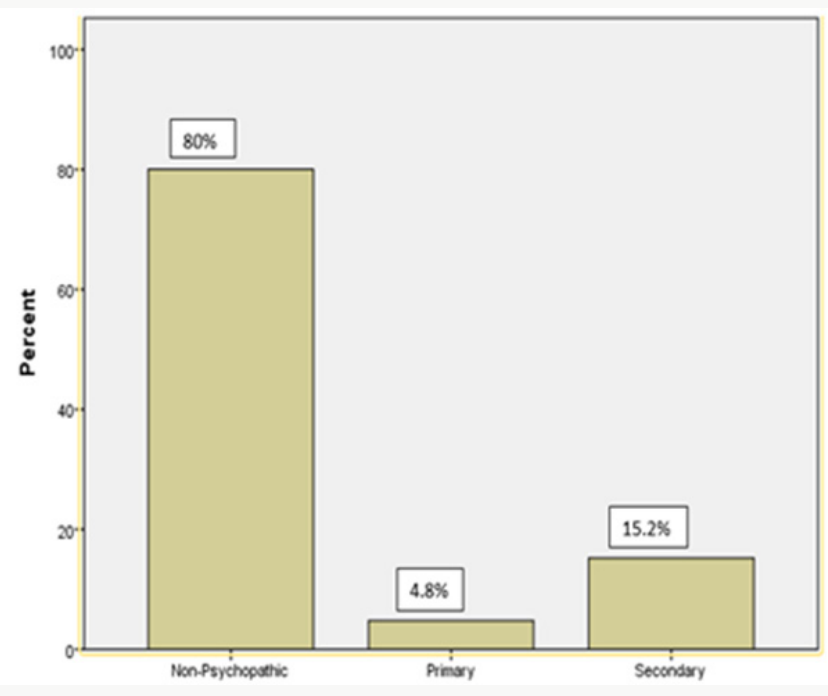

Figure 1: Distribution of Non-Psychopathic and Primary and Secondary Psychopathic-Like Youth in General Population Sample $(\mathrm{N}=1,364)$.

Obviously, the numbers of psychopathic youth presented in (Figure 1) is greater than other estimates that indicated that psychopaths only represent $1 \%$ of the general population. Several reasons may underlie the discrepancy. It may be that the $20 \%$ figure (or $4.8 \%$ of the primary group) is capturing some of the dark figure of undercounted psychopaths (the dark figure of psychopathy), but it may also be that youth demonstrate a number of tendencies that may map onto the measurement scheme for psychopathy. There is also reasonable evidence that youth may grow out of some of the characteristics that would count them as psychopathic by some measures, which is demonstrated in the stability research. Youth who are dissociative may also be captured by measures aimed at psychopathy, which would result in them being included under the umbrella of psychopathic-like. It is equally plausible that the $1 \%$ estimate of psychopathy noted in some literature is incorrect or an underestimate because of reasons associated with measurement and conception.

Concerning the notion that some characteristics of youth may map on to certain features of psychopathy, yet be a part of normal development (e.g., narcissism, impulsivity); while these concerns manifest in discussions among scholars, there are those that believe such apprehensions are exaggerated [10] as clinicians should be able to distinguish normal development from features of psychopathy $[11,12]$. However, not all clinicians are created equal, and it is not uncommon for a single individual to receive different diagnosis depending upon which specialist is seen. Assuming that all clinicians are created equal, then, may be in error. Just as problematic would be going to a clinician who may over-diagnose juvenile psychopathy. Complicating matters further, given an accurate diagnosis, how would such youth be offered treatment? How would others, institutions, officials respond to such a youth?

On a final note, irrespective of the controversies and problems noted here, it is very clear that there is a persistent desire to find answers. There is progress being made and a number of thoughtful scholars recognize the problems manifest in the study of juvenile psychopathy. It cannot be ignored that in spite of the tremendous amount of research examining developmental psychopathy across a multitude of specialties and theoretical perspectives, there appears to be more questions than answers. This does not mean that we do not know anything about nascent psychopathy. It does alert to the idea that there is significantly more work to do.

\section{References}

1. Skeem JL, Cooke DJ (2010a) Is criminal behavior a central component of psychopathy? Conceptual directions for resolving the debate. Psychological Assessment 22(2): 433-445.

2. Skeem JL, Cooke DJ (2010b) One measure does not a construct make: Directions toward reinvigorating psychopathy research-A reply to Hare and Neumann. Psychological Assessment 22(2): 455-459.

3. Cleckley H $(1941,1976)$ The mask of sanity ( $5^{\text {th }}$ edn.), St. Louis, MO; C.V. Mosby pp 267-272.

4. Hare RD, Neumann C (2010) The role of antisociality in the psychopathy construct: Comment on Skeemand Cooke. Psychological Assessment 22(2): 446-454.

5. Hare RD, Neumann CS (2005) The structure of psychopathy. Current Psychiatry Reports 7(1): 57-64.

6. Gao Y, Raine A (2010) Successful and unsuccessful psychopaths: A neurobiological model. Behavioral Sciences \& the Law 28(2): 194-210.

7. Karpman B (1941) On the need of separating psychopathy into two distinct clinical types: The symptomatic and the idiopathic. Journal of Criminal Psychopathology 3: 112-137.

8. Flexon JL (2014) Evaluating Variant Callous-Unemotional Traits among Non-institutionalized Youth: Implications for Violence Research and Policy. Youth Violence and Juvenile Justice 13: 18-40.

9. Andershed H, Kerr M, Stattin H, Levander S (2012) Psychopathic traits in non-referred youths: A new assessment tool. In: E Blauuw, L Sheridan (Eds.), Psychopaths: Current international perspectives pp. 131-158.

10. Lynam DR, Gudonis L (2005) The development of psychopathy. Annual Review of Clinical Psychology 1: 381-407.

11. Michonski JD, Sharp C (2010) Revisiting Lynam's notion of the "Fledgling Psychopath": Are HIA-CP children truly psychopathic-like? Child and Adolescent Psychiatry and Mental Health 4: 1-9.

12. Flexon JL (2015) Callous-Unemotional Traits and Differently Motivated Aggression. Youth Violence and Juvenile Justice 14(4): 367-389. 


\section{(c) (i) This work is licensed under Creative}

To Submit Your Article Click Here: Submit Article

DOI: 10.32474/PRJFGS.2018.01.000117

\begin{tabular}{|c|c|}
\hline PRJFGS & $\begin{array}{l}\text { Peer Reviewed Journal of Forensic } \\
\text { \& Genetic Sciences }\end{array}$ \\
\hline & $\begin{array}{l}\text { Assets of Publishing with us } \\
\text { - } \quad \text { Global archiving of articles } \\
\text { - Immediate, unrestricted online access } \\
\text { - } \quad \text { Rigorous Peer Review Process }\end{array}$ \\
\hline 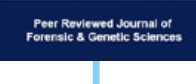 & $\begin{array}{l}\text { - Authors Retain Copyrights } \\
\text { - Unique DOI for all articles }\end{array}$ \\
\hline
\end{tabular}

